\title{
A Coordination Model Under an Order-Up-To Policy
}

\author{
Jong Soo KIM ${ }^{1}$, Won Chan JEONG ${ }^{2}$ \\ ${ }^{1}$ Department of Industrial and Management Engineering, Hanyang University, Erica Campus \\ Sa 3-dong, Sangnok-gu, Ansan-si, 426-791, South Korea \\ ${ }^{2}$ Department of Industrial and Management Engineering, Graduate School, Hanyang University \\ Haengdang 1-dong, Seongdong-gu, Seoul, 133-791, South Korea \\ e-mail:pure@hanyang.ac.kr,wcjeong@mecors.hanyang.ac.kr
}

Received: January 2011; accepted: September 2011

\begin{abstract}
A logistics system that involves a supplier who produces and delivers a single product and a buyer who receives and sells the product to the final customers was analyzed. A mathematical model was developed to describe the behavior of the system and to derive the optimal cycle length and order-up-to levels for the two parties. An analysis of the obtained results revealed that the methods were able to determine the optimal control parameters for each party in a short time frame. A coordination mechanism based on the optimal policies was ultimately proposed so that each party benefits more than if they use their own optimal control policy.
\end{abstract}

Keywords: inventory control, buyer-supplier model, stochastic demand, periodic policy.

\section{Introduction}

In this study, a logistics and production system associated with a long-term contract between a single supplier and a single buyer is examined. The system depends on a supplier who produces and delivers a single product and a buyer who receives and sells the product to the end customers. In this system, the supplier and the buyer construct a contract which specifies that the supplier will deliver a specific amount of the product at the start of each time period.

The terms of the contract determine when and how much of the product will be delivered, as negotiated by the two contracting parties. The buyer and supplier both aim to establish terms that minimize operating costs and maximize profit. When both parties aim to maximize profit, one party's target outcome commonly contradicts that of the other, yielding less than the maximum achievable outcomes for both parties.

Many coordination mechanisms with the potential to yield benefits for both parties have been proposed in previous studies. However, much of this research has focused on deterministic demand. A few models based on stochastic demand also left room for improvement because these works fell into the class of approximation methods. In this work, a mathematical model for a system with stochastic demand is proposed based on both the supplier's and the buyer's perspectives. Based on this model, algorithms 
were derived to determine the optimal control parameters, including the optimal order size and timing of each party. A coordination mechanism is proposed to improve the efficiency of the entire system and to enable both parties to reach a desirable outcome.

Previous research related to the aforementioned topic has been categorized as the buyer-vendor coordination problem in reference to the quantity discount policy used by vendors to force buyers to accept the lot size imposed by the vendor. This problem was first studied by Crowther (1964) in an analysis of the profit gained by the vendor when enticing the buyer with a price discount on order quantities larger than the economic order quantity (EOQ). Such work was followed by several other studies that addressed similar problems from a different perspective or in a more complex setting. This research included works by Monahan (1984), Rosenblatt and Lee (1985), Benerjee (1986), Goyal (1987), Anupindi and Akella (1993), Lu (1995), Goyal (1995), and Hill (1997). These studies are similar in that the researchers focused on the discount-schedule problem using a single buyer and a single supplier environment with a deterministic demand. The exceptions are the studies of Anupindi and Akella (199 3), Goyal (1995), and Lu (1995), in which ordering policies with a single buyer and a multiple vendor system were examined. A detailed review of the available approaches for the coordination of single buyer and single supplier systems is available in a report by Sharafali and Co (2000).

Subsequent to the research of Sharafali and Co (2000), more complex systems such as supply chain systems have been investigated. Specifically, Gurnani (2001), Viswanathan and Piplani (2001), Klastorin et al. (2002), Kim et al. (2002), and Mishra (2004) examined methods for coordinating systems with multiple suppliers or multiple buyers. Munson and Rosenblatt (2001) and Khouja (2003) studied a coordination problem in a multi-stage system. Bendaya and Hariga (2004) analyzed a system with a single vendor and a single buyer motivated by a probabilistic demand and a variable lead time. Ouyang et al. (2004) presented two models of a similar system and presented effective iterative procedures for determining the optimal policy. The majority of previous research conducted on this topic (with the exception of a few studies, such as those by Bendaya (2004) and Ouyang et al. (2004)) has focused on deterministic demand characteristics. For an extensive review of the literature on buyer-supplier co ordination in supply chain management (Sarmah et al., 2006).

More recently, Eynan and Kropp (2007) examined a periodic review system with a single buyer and a single supplier in a stochastic demand setting. The researchers proposed a simple heuristic capable of generating a solution close to the optimum. (For a general discussion of the application of heuristic methods - Dzemyda and Sakalauskas, 2010.) In the current work, a system resembling that studied by Eynan and Kropp (2007) is considered.

The research presented here contributes to the existing body of literature in two ways. The first contribution is the analysis of a system with stochastic demand. Such an analysis allows for the construction of mathematical models from buyer and supplier perspectives. The models are unique in that they include a target service level constraint for a buyer. 
Based on the developed models, algorithms were derived to simultaneously determine the replenishment cycle and replenishment amount so as to minimize a total cost and, at the same time, satisfy the given target service constraint.

To the best of our knowledge, the algorithm proposed here is the first approach with the capability to simultaneously optimize these two terms which also satisfy the service constraint. The second contribution of this work is the development of a coordination and profit allotment mechanism to increase the efficiency of the system.

The problem addressed in this study is defined in Section 2, while mathematical models and algorithms are introduced in Section 3. The results obtained from computer experiments and the coordination mechanism are presented in Section 4. Conclusions and avenues for future research are outlined in the final section.

\section{Problem Statement}

In the system examined in this work, the buyer tries to maximize profit by selling a type of product according to a stochastic demand from the end customers. The buyer contracts with a supplier in order to purchase the product regularly in accordance with the inventory control policy. The supplier manufactures the product in response to the orders from the buyer.

The periodic inventory control policy frequently used by the buyer in this type of system includes an order-up-to-level policy known as $(R, S)$ policy. This policy has been shown to be efficient and practical in real world applications. Using this policy, a buyer regularly purchases a product such that the inventory position following replenishment increases to the specified level, $S$. In the next section, mathematical models for each party are introduced.

The following is a list of necessary notations.

$R$ - review interval,

$L$ - lead time needed for replenishment orders to arrive at the buyer's location,

$k_{b}$ - safety factor used for determining the safety stock of the buyer,

$D$ - annual demand rate of the end customers,

$\sigma$ - standard deviation of $D$,

$A$ - buyer's ordering cost per order,

$h_{b}$ - buyer's holding cost per unit per year,

$b_{b}$ - buyer's shortage cost per unit,

$s_{b}$ - buyer's order-up-to level,

$B$ - supplier's setup cost per production batch,

$h_{s}$ - supplier's holding cost per completed unit per year,

$b_{s}$ - supplier's shortage cost per unit,

$k_{s}$ - safety factor used for determining the safety stock of the supplier,

$\rho$ - supplier's production rate per year,

$s_{s}$ - supplier's produce-up-to level,

$T C_{b}$ - total cost per year incurred by the buyer,

$T C_{s}$ - total cost per year incurred by the supplier. 


\section{Optimal Policy for Each Party}

\subsection{Supplier's Optimal Policy}

Since the supplier does not know the exact amount to deliver until the delivery time, inventory is produced up to a predetermined level at each period. Since the end customer's demand in the real world can usually be modeled with a normal distribution, it is assumed here that the buyer's end customer demand per period is normally distributed with a mean of $D R$ and a variance of $\sigma^{2} R$.

The average supply amount is equal to average per period demand at the buyer's site, thus, is $D R$. When the supplier sets the highest inventory point, i.e., the produce-up-to level, to be the average supply amount considering this fact, there will be a shortage of supply for half of the cycles (half of the per period demand will exceed the mean value). Therefore, the supplier must have a safety stock for protection against such a shortage. The supplier's inventory change in this situation is shown in Fig. 1.

It is a common practice to establish a safety stock equal to the safety factor multiplied by the standard deviation of the demand. When the supplier applies such a rule, the standard deviation of the supplier's delivery amount is used for determining the safety stock level. The standard deviation of the delivery amount is equal to that of the end customer's demand on the buyer; it is thus expressed as $\sigma \sqrt{R}$. Thus the aforementioned method of establishing a safety stock level leads to a safety stock level of $k_{s} \sigma \sqrt{R}$.

To calculate the average holding cost per period, the area under inventory graph for a period must be found. In Fig. 1, the average length of I is $D R / \rho$, the average height of II is $D R$, and the safety stock level denoted by III is $k_{s} \sigma \sqrt{R}$. Thus, the average area for a period can be expressed as

$$
\frac{D^{2} R^{2}}{2 \rho}+k_{s} \sigma R^{\frac{3}{2}}
$$

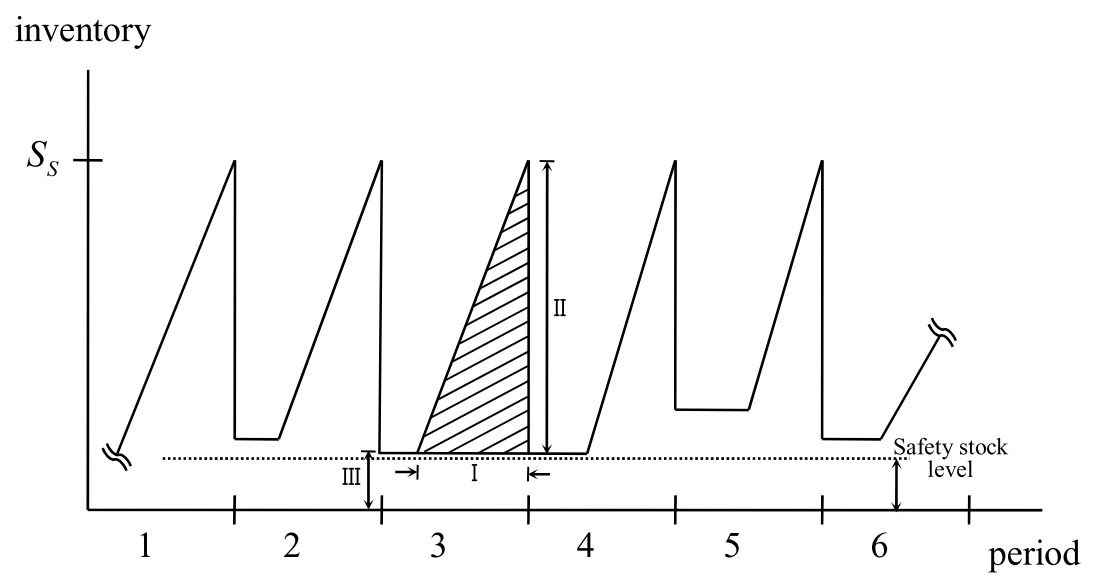

Fig. 1. Supplier's changes in inventory. 
The expected annual holding cost will be the value obtained from (1) multiplied by $h_{s}$ and the number of cycles in a year.

Although the supplier takes protective measures against an unexpected increase in the delivery amount, it is still possible that a shortage in the necessary delivery amount will arise. In this case, the supplier must outsource the amount of shortage to complete the delivery. Compared to a normal delivery from the supplier's own inventory, this type of outsourcing usually incurs additional costs. This cost incurred by the outsourcing will be called the shortage cost of the supplier.

To determine an equation for the shortage cost of the supplier, an expression for the expected number of shortages per cycle must first be derived. The expected number of shortages per cycle is

$$
\int_{s_{s}}^{\infty}\left(x-s_{s}\right) g(x) \mathrm{d} x
$$

where

$$
s_{s}=D R+k_{s} \sigma \sqrt{R}
$$

and $x$ denotes the demand during a cycle. Because it was assumed that $x \sim N\left(D R, \sigma^{2} R\right)$, its probability distribution is

$$
g(x)=\frac{1}{\sqrt{2 \pi} \sigma \sqrt{R}} e^{-\frac{(x-D R)^{2}}{2(\sigma \sqrt{R})^{2}}}
$$

By setting

$$
\begin{aligned}
& z=\frac{x-D R}{\sigma \sqrt{R}}, \\
& \mathrm{~d} x=\sigma \sqrt{R} \mathrm{~d} z .
\end{aligned}
$$

Thus,

$$
\begin{aligned}
\int_{s_{s}}^{\infty} & \left(x-s_{s}\right) g(x) \mathrm{d} x \\
= & \int_{D R+k_{s} \sigma \sqrt{R}}^{\infty}\left(x-D R-k_{s} \sigma \sqrt{R}\right) g(x) \mathrm{d} x \\
= & \int_{D R+k_{s} \sigma \sqrt{R}}^{\infty}\left(z \sigma \sqrt{R}-k_{s} \sigma \sqrt{R}\right) g(x) \mathrm{d} x
\end{aligned}
$$




$$
\begin{aligned}
& =\int_{k_{s}}^{\infty}\left(z \sigma \sqrt{R}-k_{s} \sigma \sqrt{R}\right) \frac{1}{\sqrt{2 \pi} \sigma \sqrt{R}} e^{-\frac{z^{2}}{2}} \sigma \sqrt{R} \mathrm{~d} z \\
& =\sigma \sqrt{R} \int_{k_{s}}^{\infty}\left(z-k_{s}\right) \frac{1}{\sqrt{2 \pi}} e^{-\frac{z^{2}}{2}} \mathrm{~d} z \\
& =\sigma \sqrt{R} \int_{k_{s}}^{\infty}\left(z-k_{s}\right) f(z) \mathrm{d} z \\
& =\sigma \sqrt{R}\left(f\left(k_{s}\right)-k_{s}\left(1-F\left(k_{s}\right)\right)\right. \\
& =\sigma \sqrt{R} G_{u}\left(k_{s}\right),
\end{aligned}
$$

where $f(z)=\frac{1}{\sqrt{2 \pi}} e^{-\frac{z^{2}}{2}}, F\left(k_{s}\right)=\int_{-\infty}^{k_{s}} f(z) \mathrm{d} z$, and $G_{u}\left(k_{s}\right)$ is unit normal loss function.

The annual shortage cost is the result obtained from (5) multiplied by the per unit shortage cost and the number of cycles in a year:

$$
\frac{b_{s} \sigma G_{u}\left(k_{s}\right)}{\sqrt{R}}
$$

Thus, the expected total annual cost to the supplier is

$$
T C_{s}\left(R, k_{s}\right)=\frac{B}{R}+\frac{D^{2} R h_{s}}{2 \rho}+k_{s} \sigma \sqrt{R} h_{s}+\frac{b_{s} \sigma G_{u}\left(k_{s}\right)}{\sqrt{R}} .
$$

To minimize costs, the supplier needs to determine the $R$ and $k_{s}$ values that minimize the cost function in (7). As shown in (A.1) in Appendix 1, the optimal $R$ value should satisfy the following first necessary condition of a minimum point.

$$
\frac{B}{R^{2}}=\frac{D^{2} h_{s}}{2 \rho}+\frac{\sigma\left(k_{s} h_{s} R-b_{s} G_{u}\left(k_{s}\right)\right)}{2 R \sqrt{R}} .
$$

The $R$ value satisfying (8) can be a local optimal cycle length and is a global optimum when the condition (A.3) in Appendix 1 is met.

Partial differentiation of (7) with respect to $k_{s}$ yields the following equation.

$$
\frac{\partial T C_{s}}{\partial k_{s}}\left(R, k_{s}\right)=\sigma h_{s} \sqrt{R}-\frac{\sigma b_{s}\left(1-F\left(k_{s}\right)\right)}{\sqrt{R}} .
$$

Thus, optimal $R$ and $k_{s}$ values should satisfy the following expression.

$$
R=\frac{b_{s}}{h_{s}}\left(1-F\left(k_{s}\right)\right)
$$

where $R \geqslant 0$ is guaranteed because $F\left(k_{s}\right) \leqslant 1$. 
Substituting (10) into (8) results in the following equation.

$$
\begin{gathered}
\frac{B}{\left(\left(b_{s} / h_{s}\right)\left(1-F\left(k_{s}\right)\right)\right)^{2}}-\frac{D^{2} h_{s}}{2 \rho} \\
-\frac{\sigma\left(k_{s} h_{s}\left(\left(b_{s} / h_{s}\right)\left(1-F\left(k_{s}\right)\right)\right)-b_{s} G_{u}\left(k_{s}\right)\right)}{2\left(\left(b_{s} / h_{s}\right)\left(1-F\left(k_{s}\right)\right)\right) \sqrt{\left(b_{s} / h_{s}\right)\left(1-F\left(k_{s}\right)\right)}}=0 .
\end{gathered}
$$

A $k_{s}$ value satisfying (11) can be attained using Microsoft Excel or a search technique such as the bisection method. By inserting this $k_{s}$ value into (10), a corresponding $R$ value can be obtained. This $R, k_{s}$ set is the minimum cost cycle length and safety factor for the supplier. The following algorithm summarizes the process for determining this $R, k_{s}$ set.

\section{Algorithm RK_Supplier}

Step 1 . Determine the minimum cost $k_{s}$ value by solving (11).

Step 2. Determine a corresponding $R$ value using (10). Generate an $R, k_{s}$ set as the solution to the problem.

\subsection{Buyer's Optimal Policy}

The buyer's total costs consist of ordering, holding, and shortage costs. The total ordering cost per year is the ordering cost per period divided by $R$, i.e.,

$$
\frac{A}{R}
$$

Figure 2 shows a plot of the buyer's inventory change; the average length of I is the average demand per cycle and may be expressed as $D R$. The height denoted by II is

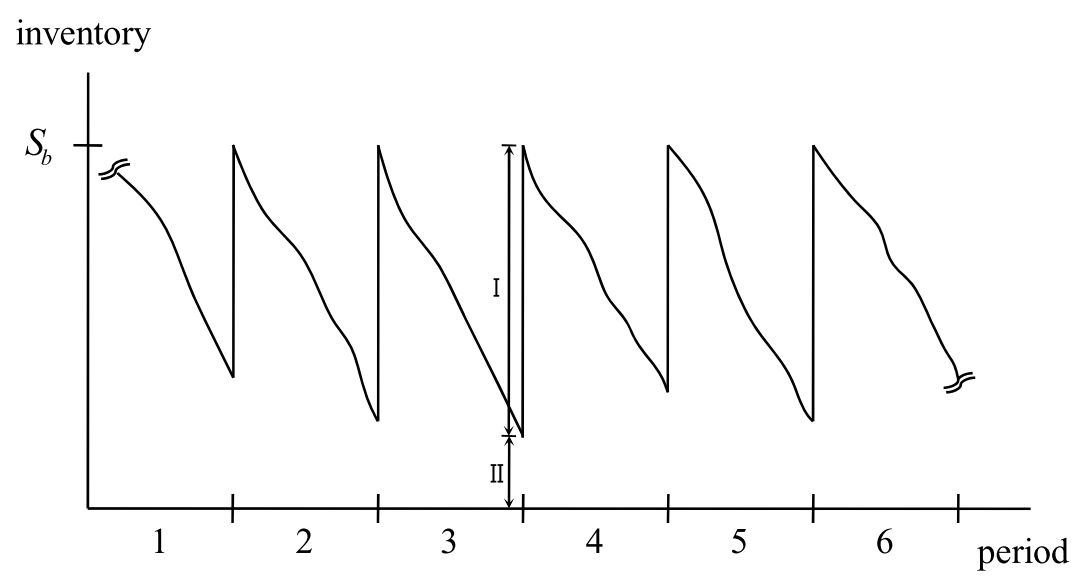

Fig. 2. Buyer's changes in inventory. 
the average inventory remaining before a replenishment delivery arrives. By definition, II represents the safety stock level of the buyer.

When $k_{b}$ is used to denote the safety factor of the buyer, the safety stock level is expressed as

$$
k_{b} \sigma \sqrt{R+L}
$$

Thus, the average height of the inventory maintained per year is expected value of $\frac{I}{2}+I I$. Thus it is

$$
\frac{D R}{2}+k_{b} \sigma \sqrt{R+L}
$$

The holding cost per year is the value determined from (14) multiplied by the per unit holding cost; it may be expressed as

$$
h_{b}\left(\frac{D R}{2}+k_{b} \sigma \sqrt{R+L}\right) .
$$

A shortage occurs when the end customer's demand exceeds the order-up-to level of the buyer. Thus, the expected number of shortages per cycle is

$$
\int_{s_{b}}^{\infty}\left(y-s_{b}\right) \eta(y) \mathrm{d} y .
$$

The expected shortage cost per year is

$$
\frac{b}{R} \int_{s_{b}}^{\infty}\left(y-s_{b}\right) \eta(y) \mathrm{d} y
$$

In (17),

$$
s_{b}=D(R+L)+k_{b} \sigma \sqrt{R+L}
$$

and $y$ denotes the end customer's demand for a time length of $R+L$. Since it was assumed that $y$ is normally distributed with a mean of $D(R+L)$ and a standard deviation of $\sigma \sqrt{R+L}$, its probability distribution is expressed as

$$
\eta(y)=\frac{1}{\sqrt{2 \pi} \sigma \sqrt{R+L}} e^{-\frac{(y-D(R+L))^{2}}{2(\sigma \sqrt{R+L})^{2}}} .
$$

By setting

$$
z=\frac{y-D(R+L)}{\sigma \sqrt{R+L}},
$$


we have

$$
\mathrm{d} y=\sigma \sqrt{R+L} \mathrm{~d} z
$$

Using (18) through (21), (17) can be rewritten as

$$
\begin{aligned}
& \frac{b_{b}}{R} \int_{s_{b}}^{\infty}\left(y-s_{b}\right) \eta(y) \mathrm{d} y \\
& \quad=\frac{b_{b}}{R} \int_{D(R+L)+k_{b} \sigma \sqrt{R+L}}^{\infty}\left(y-D(R+L)-k_{b} \sigma \sqrt{R+L}\right) \eta(y) \mathrm{d} y \\
& =\frac{b_{b}}{R} \int_{k_{b}}^{\infty}\left(z \sigma \sqrt{(R+L)}-k_{b} \sigma \sqrt{R+L}\right) \frac{1}{\sigma \sqrt{2 \pi} \sqrt{R+L}} e^{-\frac{z^{2}}{2}} \sigma \sqrt{R+L} \mathrm{~d} z \\
& =\frac{b_{b}}{R} \sigma \sqrt{(R+L)} \int_{k_{b}}^{\infty}\left(z-k_{b}\right) f(z) \mathrm{d} z \\
& =\frac{b_{b}}{R} \sigma \sqrt{(R+L)} G_{u}\left(k_{b}\right) .
\end{aligned}
$$

Thus, the total cost to the buyer is

$$
T C_{b}\left(R, k_{b}\right)=\frac{A}{R}+h_{b}\left(\frac{D R}{2}+k_{b} \sigma \sqrt{R+L}\right)+\frac{b_{b}}{R} \sigma \sqrt{R+L} G_{u}\left(k_{b}\right)
$$

To calculate the $R, k_{b}$ values that minimize the cost function in (23), first necessary condition of minimum point is used. A partial differentiation with respect to $k_{b}$ yields

$$
\frac{\partial T C_{b}}{\partial k_{b}}\left(R, k_{b}\right)=h_{b} \sigma \sqrt{R+L}-\frac{b_{b}}{R} \sigma \sqrt{R+L}\left(1-F\left(k_{b}\right)\right) .
$$

By setting

$$
\frac{\partial T C_{b}}{\partial k_{b}}\left(R, k_{b}\right)=0
$$

we obtain the following relationship that must be satisfied by the optimal $R, k_{b}$ values:

$$
1-F\left(k_{b}\right)=\frac{h_{b}}{b_{b}} R
$$

or

$$
R=\frac{b_{b}}{h_{b}}\left(1-F\left(k_{b}\right)\right)
$$


Partial differentiation of (23) with respect to $R$ gives

$$
\frac{\partial T C_{b}}{\partial R}\left(R, k_{b}\right)=-\frac{A}{R^{2}}+\frac{D h_{b}}{2}+\frac{k_{b} \sigma h}{2 \sqrt{R+L}}-\frac{b_{b} \sigma G_{u}\left(k_{b}\right)}{2}\left(\frac{R+2 L}{R^{2} \sqrt{R+L}}\right) .
$$

By setting

$$
\frac{\partial T C_{b}}{\partial R}\left(R, k_{b}\right)=0
$$

we obtain

$$
\frac{k_{b} \sigma h_{b}}{2 \sqrt{R+L}}-\frac{b_{b} \sigma G_{u}\left(k_{b}\right)}{2}\left(\frac{R+2 L}{R^{2} \sqrt{R+L}}\right)=\frac{A}{R^{2}}-\frac{D h_{b}}{2} .
$$

Substituting (27) into (30) gives

$$
\begin{aligned}
& \frac{k_{b} \sigma h_{b}}{2 \sqrt{\left(b_{b} / h_{b}\right)\left(1-F\left(k_{b}\right)\right)+L}} \\
& -\frac{b_{b} \sigma G_{u}\left(k_{b}\right)}{2}\left(\frac{\left(b_{b} / h_{b}\right)\left(1-F\left(k_{b}\right)\right)+2 L}{\left(b_{b} / h_{b}\right)^{2}\left(1-F\left(k_{b}\right)\right)^{2} \sqrt{\left(b_{b} / h_{b}\right)\left(1-F\left(k_{b}\right)\right)+L}}\right) \\
& -\frac{A}{\left(\left(b_{b} / h_{b}\right)\left(1-F\left(k_{b}\right)\right)\right)^{2}}+\frac{D h_{b}}{2}=0 .
\end{aligned}
$$

Using Microsoft Excel, a $k_{b}$ value satisfying (31) can be obtained (such a $k_{b}$ value can also be found using a general search method because the search area can be confined to practically feasible values of $k_{b}$ ). By substituting the value of $k_{b}$ into (27), a corresponding $R$ value can be found. This $R, k_{b}$ set can be a cost minimizing cycle length and safety factor for the buyer considering cost alone.

The buyer's use of the above $R, k_{b}$ set (which seeks cost minimization alone) may lead to an unacceptably low customer service level. Thus it is a common practice for the retailer to pursue a cost minimizing objective as a second priority and to attempt to achieve a target service level first. Considering this practice, the final solution for the buyer is defined as the $R, k_{b}$ set that satisfies the target customer service level at the minimum cost.

An algorithm to determine the final amount that satisfies a preset target service level at minimum cost is introduced below. The minimum cost $k_{b}$ value is denoted as $k_{b}^{\mathrm{min}}$, and the target customer service level is represented by $k_{b}^{\text {target }}$.

\section{Algorithm RK_Buyer}

Step 1. Determine the minimum cost $k_{b}$ value with (31) and save the value in $k_{b}^{\min }$

Step 2. If $k_{b}^{\mathrm{min}} \geqslant k_{b}^{\text {target }}$, go to Step 3. Otherwise, go to Step 4.

Step 3. Set $k_{b} \leftarrow k_{b}^{\text {min }}$ and use (27) to find the corresponding $R$ value. Generate an $R, k_{b}$ set as the solution to the problem. Stop. 
Step 4. Set $k_{b} \leftarrow k_{b}^{\text {target }}$ and use (27) to find the corresponding $R$ value. Generate an $R, k_{b}$ set as the solution to the problem. Stop.

In Step 2, a check is performed to determine if the minimum cost $k_{b}$ value is greater than the target customer service level. If it is, the $R, k_{b}$ set which yields the minimum cost also satisfies the target service level due to the property that the cost function is convex with respect to $k_{b}$ and this set can be accepted as the final solution (see Appendix 2 for a proof). Step 4 represents a case in which the minimum cost $k_{b}$ does not satisfy the target service level. In such a case, the given target customer service level is the level satisfying the target at minimum cost.

As shown in Appendix 2, the buyer's cost function is convex with respect to $k$ but not with respect to $R$. Thus, the solution generated by algorithm RK_Buyer is not assured to be a global optimal solution. As outlined in the following section, computer experiments were performed to examine how close the solution is to the global optimal solution.

\section{Computer Experiments}

\subsection{Efficiency Test of Algorithm RK_Supplier}

In this section, an investigation into how close the solution of RK_ Supplier is to the global optimal solution was performed. The experiments were conducted on a computer with a Microsoft XP operating system, a 2.0 MHz CPU, and $2 \mathrm{~GB}$ of RAM. The algorithm RK_Buyer was programmed into Microsoft Excel. A complete enumeration was used to obtain the global optimal solution.

A modified version of the data from Eynan and Kropp (2007), in which a similar problem was studied, was used for the input of the test. A percent deviation of the total cost was used as a measure of performance; it is defined as:

$$
\text { Percent deviation }=100\left(T C-T C^{*}\right) / T C^{*},
$$

where $T C$ is the total cost of our solution and $T C^{*}$ is the total cost of the global optimum solution obtained by a complete enumeration. Using the input shown in Table 1, the results in Table 2 were obtained. The 0.000 percent deviation in the results indicates that our algorithm could find a solution very close to the global optimum solution for all six cases. The average computational time of RK_Supplier for a set of problems was recorded to be less than 1 second in real computational time.

\subsection{Efficiency Test of Algorithm RK_Buyer}

Algorithm RK_Buyer was also tested for its efficiency. Similarly to the previous experiments, data from Eynan and Kropp (2007) were selected as the input parameters (see Table 3). The data contain input parameter values for 21 different settings. For the initial test, a target service level of zero was assumed. 
Table 1

Inputs of RK_Supplier

\begin{tabular}{llllll}
\hline Input & & & & & \\
\hline $\begin{array}{l}\text { Setup } \\
\text { cost }\end{array}$ & $\begin{array}{l}\text { Holdings } \\
\text { cost }\end{array}$ & $\begin{array}{l}\text { Annual } \\
\text { demand }\end{array}$ & $\begin{array}{l}\text { Standard } \\
\text { deviation }\end{array}$ & $\begin{array}{l}\text { Production } \\
\text { rate }\end{array}$ & $\begin{array}{l}\text { Shortage } \\
\text { cost }\end{array}$ \\
\hline 100 & 0.2 & 4,000 & 882 & 8,000 & 8 \\
100 & 0.2 & 4,000 & 1,547 & 8,000 & 8 \\
100 & 0.2 & 4,000 & 849 & 8,000 & 80 \\
100 & 0.2 & 4,000 & 871 & 8,000 & 16 \\
100 & 0.2 & 4,000 & 897 & 8,000 & 4 \\
100 & 0.2 & 4,000 & 948 & 8,000 & 0.8 \\
\hline
\end{tabular}

Table 2

Outputs of RK_Supplier

\begin{tabular}{llll}
\hline Output & & & \\
\hline $\begin{array}{l}\text { Safety } \\
\text { factor }\end{array}$ & $\begin{array}{l}\text { Cycle } \\
\text { length }\end{array}$ & $\begin{array}{l}\text { Total } \\
\text { cost }\end{array}$ & $\begin{array}{l}\text { Percenty } \\
\text { deviation }\end{array}$ \\
\hline 2.262 & 0.474 & 622.403 & 0.000 \\
2.350 & 0.376 & 850.768 & 0.000 \\
3.076 & 0.420 & 691.131 & 0.000 \\
2.532 & 0.454 & 645.780 & 0.000 \\
1.960 & 0.499 & 596.562 & 0.000 \\
1.014 & 0.621 & 518.801 & 0.000 \\
\hline
\end{tabular}

Algorithm RK_Buyer was used to obtain $R, k_{b}$ values for each setting. For each pair of attained values, a corresponding buyer's objective function value was determined using (23). The percent deviation defined in (32) was used for the performance measure.

The results shown in Table 4 reveal that our solution coincides with the global optimum solution in 21 cases. In other words, the proposed algorithm successfully generated global optimal solutions for all cases. In contrast, the performance of the heuristic method developed by Eynan and Kropp (2007) found an optimal solution in only one of 21 cases. Our method is thus superior in its ability to determine the global optimum solution. The average computational time of RK_Buyer for a set of problems was recorded to be less than 1 second in real computational time.

Before concluding the experiments, another test was performed to examine the performance of the RK_Buyer algorithm in a non-zero target service level environment. For this test, the input parameters in Table 5 were used. These parameters were randomly sampled from data in the aforementioned report by Eynan and Kropp (2007). The target service level was selected to be 1.96 , corresponding to a situation in which 97.5 of 100 incoming customers can purchase the product without backlogging. The output of the experiment 
Table 3

Inputs of RK_Buyer with $k_{b}^{\text {target }}=0$

\begin{tabular}{|c|c|c|c|c|c|}
\hline \multicolumn{6}{|l|}{ Input } \\
\hline $\begin{array}{l}\text { Setup } \\
\text { cost }\end{array}$ & $\begin{array}{l}\text { Holdings } \\
\text { cost }\end{array}$ & $\begin{array}{l}\text { Annual } \\
\text { demand }\end{array}$ & $\begin{array}{l}\text { Standard } \\
\text { deviation }\end{array}$ & $\begin{array}{l}\text { Lead } \\
\text { time }\end{array}$ & $\begin{array}{l}\text { Shortage } \\
\text { cost }\end{array}$ \\
\hline 100 & 0.20 & 4,000 & 882 & 0.05 & 8.0 \\
\hline 1,000 & 0.20 & 4,000 & 1,547 & 0.05 & 8.0 \\
\hline 200 & 0.20 & 4,000 & 1,038 & 0.05 & 8.0 \\
\hline 50 & 0.20 & 4,000 & 756 & 0.05 & 8.0 \\
\hline 10 & 0.20 & 4,000 & 549 & 0.05 & 8.0 \\
\hline 100 & 2.00 & 4,000 & 572 & 0.05 & 8.0 \\
\hline 100 & 0.40 & 4,000 & 766 & 0.05 & 8.0 \\
\hline 100 & 0.10 & 4,000 & 1,023 & 0.05 & 8.0 \\
\hline 100 & 0.02 & 4,000 & 1,468 & 0.05 & 8.0 \\
\hline 100 & 0.20 & 40,000 & 5,483 & 0.05 & 8.0 \\
\hline 100 & 0.20 & 8,000 & 1,511 & 0.05 & 8.0 \\
\hline 100 & 0.20 & 2,000 & 519 & 0.05 & 8.0 \\
\hline 100 & 0.20 & 400 & 155 & 0.05 & 8.0 \\
\hline 100 & 0.20 & 4,000 & 1,032 & 0.20 & 8.0 \\
\hline 100 & 0.20 & 4,000 & 1,220 & 0.42 & 8.0 \\
\hline 100 & 0.20 & 4,000 & 1,566 & 0.92 & 8.0 \\
\hline 100 & 0.20 & 4,000 & 2,366 & 2.52 & 8.0 \\
\hline 100 & 0.20 & 4,000 & 849 & 0.05 & 80.0 \\
\hline 100 & 0.20 & 4,000 & 871 & 0.05 & 16.0 \\
\hline 100 & 0.20 & 4,000 & 897 & 0.05 & 4.0 \\
\hline 100 & 0.20 & 4,000 & 948 & 0.05 & 0.8 \\
\hline
\end{tabular}

is shown in Table 6. In all five cases, the RK_Buyer algorithm successfully determined a solution which satisfied the given target service level at the global minimum cost. From the experiments outlined thus far, it can be concluded that the proposed algorithms can likely determine a global optimum solution in a reasonable amount of time.

\section{Coordination Mechanism}

As stated in a report by Sarmah et al. (2006), there are many kinds of supply chain coordination mechanisms depending on whether the control is centralized or decentralized, whether or not each participant belongs to the same company, or which of the two parties has a more powerful status.

Before progressing to an analysis, the system under investigation must first be characterized. It is assumed that the buyer and the supplier belong to different companies, and that each party seeks to maximize its own profit. In this situation, system-wide profit maximization is not a concern for either party. Furthermore, each party wants to make 
Table 4

Outputs of RK_Buyer with $k_{b}^{\text {target }}=0$

\begin{tabular}{llrl}
\hline Output & & & \\
\hline Safety & Cycle & \multicolumn{1}{l}{ Total } & $\begin{array}{l}\text { Percent } \\
\text { deviation }\end{array}$ \\
\hline 2.335 & length & \multicolumn{1}{c}{ cost } & 0.000 \\
1.884 & 1.303 & $2,093.369$ & 0.000 \\
2.197 & 0.560 & 994.450 & 0.000 \\
2.466 & 0.273 & 532.280 & 0.000 \\
2.747 & 0.120 & 269.400 & 0.000 \\
1.830 & 0.135 & $2,374.111$ & 0.000 \\
2.194 & 0.282 & $1,029.794$ & 0.000 \\
2.468 & 0.544 & 512.859 & 0.000 \\
2.754 & 1.177 & 231.415 & 0.000 \\
2.747 & 0.120 & $2,692.234$ & 0.000 \\
2.466 & 0.274 & $1,064.243$ & 0.000 \\
2.197 & 0.560 & 497.225 & 0.000 \\
1.844 & 1.302 & 209.493 & 0.000 \\
2.325 & 0.402 & 836.101 & 0.000 \\
2.309 & 0.418 & 998.406 & 0.000 \\
2.274 & 0.459 & $1,364.437$ & 0.000 \\
2.154 & 0.625 & $2,516.497$ & 0.000 \\
3.120 & 0.361 & 791.022 & 0.000 \\
2.593 & 0.380 & 747.355 & 0.000 \\
2.049 & 0.404 & 701.319 & 0.000 \\
1.206 & 0.456 & 629.911 & 0.000 \\
\hline
\end{tabular}

a contract to maximize their individual profit. Also we do not include quitting from negotiating for the contract as a legitimate action of either party. Lastly, it is assumed that neither party has dominant power over the other. As a consequence, neither party can force the other to accept terms that are not rational.

In the system, the buyer and the supplier aim to minimize their own costs. More specifically, the supplier wants to choose the cycle length determined by algorithm RK_Supplier, while the buyer prefers the cycle length determined by algorithm RK_Buyer. For such a conflicting situation, a coordination mechanism is proposed that enables both parties to reach an agreement superior to that attained from individual cost minimization. According to game theory, this coordination problem is a sequential movement game. The game can be either a complete information game or an incomplete information game depending on the information available.

The data in Table 7 were used for the analysis. The value of $T C_{b}\left(R_{b}\right)$ is the buyer's optimal cost and $T C_{b}\left(R_{s}\right)$ is the buyer's cost when the supplier's optimal cycle is used, and $\delta_{b}$ is the difference between the two. The values in the supplier column can be interpreted in a similar manner. 
Table 5

Inputs of RK_Buyer with $k_{b}^{\text {target }}=1.96$

\begin{tabular}{llllll}
\hline $\begin{array}{l}\text { Input } \\
\text { Setup } \\
\text { cost }\end{array}$ & $\begin{array}{l}\text { Holdings } \\
\text { cost }\end{array}$ & $\begin{array}{l}\text { Annual } \\
\text { demand }\end{array}$ & $\begin{array}{l}\text { Standard } \\
\text { deviation }\end{array}$ & $\begin{array}{l}\text { Lead } \\
\text { time }\end{array}$ & $\begin{array}{l}\text { Shortage } \\
\text { cost }\end{array}$ \\
\hline 100 & 0.20 & 4,000 & 882 & 0.05 & 8.0 \\
1,000 & 0.20 & 4,000 & 1,547 & 0.05 & 8.0 \\
100 & 2.00 & 4,000 & 572 & 0.05 & 8.0 \\
100 & 0.20 & 400 & 155 & 0.05 & 8.0 \\
100 & 0.20 & 4,000 & 948 & 0.05 & 0.8 \\
\hline
\end{tabular}

Table 6

Outputs of RK_Buyer with $k_{b}^{\text {target }}=1.96$

\begin{tabular}{llll}
\hline Output & & & \\
\hline $\begin{array}{l}\text { Safety } \\
\text { factor }\end{array}$ & $\begin{array}{l}\text { Review } \\
\text { interval }\end{array}$ & $\begin{array}{l}\text { Total } \\
\text { cost }\end{array}$ & $\begin{array}{l}\text { Percent } \\
\text { deviation }\end{array}$ \\
\hline 2.335 & 0.391 & 725.269 & 0.000 \\
1.960 & 1.000 & $2,141.209$ & 0.000 \\
1.960 & 0.100 & $2,435.844$ & 0.000 \\
1.960 & 1.000 & 214.265 & 0.000 \\
1.960 & 0.100 & $1,211.747$ & 0.000 \\
\hline
\end{tabular}

Table 7

Data for the coordination game

\begin{tabular}{llllll}
\hline Buyer & \multicolumn{5}{c}{ Supplier } \\
\hline$T C_{b}\left(R_{b}\right)$ & $T C_{b}\left(R_{s}\right)$ & $\delta_{b}$ & $T C_{s}\left(R_{s}\right)$ & $T C_{s}\left(R_{b}\right)$ & $\delta_{s}$ \\
$\$ 2,700$ & $\$ 2,800$ & 100 & $\$ 2,400$ & $\$ 2,700$ & 300
\end{tabular}

Thus

$$
\begin{aligned}
& \delta_{b}=T C_{b}\left(R_{s}\right)-T C_{b}\left(R_{b}\right), \\
& \delta_{s}=T C_{s}\left(R_{b}\right)-T C_{s}\left(R_{s}\right) .
\end{aligned}
$$

\subsection{Incomplete Information Game}

In this game, the buyer is aware of the cost to be incurred when the optimal cycle length is used. Likewise, the supplier knows the cost for his or her optimal cycle length. However, 
each player has no information on the other player's cost. Under these circumstances, the bargaining process becomes a dynamic game. To get an equilibrium solution of this game, it is necessary to divide the game into two cases: a case where the supplier's optimal cycle length is also feasible to the buyer and a case where it is not. The feasibility problem of a cycle arises because a cycle length determines the safety factor of each product type as represented by (27). Thus one or more of the safety factor of the product type can become lower than the target safety factor when the buyer tries to adopt the supplier's optimal cycle. Two cases are analyzed in detail below.

\section{Case 1: Supplier's optimal cycle is feasible to the buyer}

In this case the game evolves as shown in Fig. 3. Assuming that the minimum monetary value is $\$ 1$ and the buyer is the leader of the game, the buyer starts the game by proposing $\$ 1$ to the supplier as compensation for the cost to be incurred when the supplier accepts the optimal cycle length of the buyer. In response, the supplier either accepts the offer or makes a counteroffer worth exactly $\$ 1$ more than the previous offer. The sequence continues until the buyer offers $\$ 49$ and the supplier counteroffers $\$ 50$. At this point, the buyer rationally accepts the $\$ 50$ offer because the cost of accepting the offer $(\$ 2,750=\$ 2,800-\$ 50)$ is less than the cost incurred when a counteroffer of $\$ 51$ $(\$ 2,751=\$ 2,700+\$ 51)$ is made. The buyer can lower cost to $\$ 2,750$ after accepting the supplier's optimal cycle.

The supplier's outcome is also enhanced compared to that obtained without bargaining. The supplier could have spent $\$ 2,700$. Instead, $\$ 50$ is spent as a side payment, and the supplier is able to choose his or her optimal cycle. The final cost to the supplier is $\$ 2,450(=\$ 2,400+\$ 50)$, less than the $\$ 2,700$ that the buyer would have incurred without bargaining. In Fig. 3, backward induction can be used to verify that the result is Nash equilibrium. When the supplier is the leader of the game, the game evolves similarly. But the equilibrium solution will be $(\$ 2,749, \$ 2,451)$, which is slightly different from the previous one, $(\$ 2,750, \$ 2,450)$.

The equilibrium solution for a general type of the Case 1 game can be characterized: In the Case 1 type game, the player who was offered a side payment that equals to or exceeds the half of his or her delta value will accept the side payment and agree to choose the other party's optimal cycle. Returning to Fig. 3, the buyer accepts $\$ 50$ of the offer which equals to the half of one's own delta value. If the two delta values are equal, any player who finds the offer to him or her equal to or exceed the half of one's delta value will accept the side payment and agree to accept other player's optimal cycle.

\section{Case 2: Supplier's optimal cycle is infeasible to the buyer}

When the supplier's optimal cycle is infeasible to the buyer, the process described for the Case 1 above is not applicable because the buyer cannot meet the target safety factor when the buyer accepts the supplier's cycle. Consequently, the negotiation process looks a little different from the previous one of the Case 1. Specifically, the buyer cannot accept 


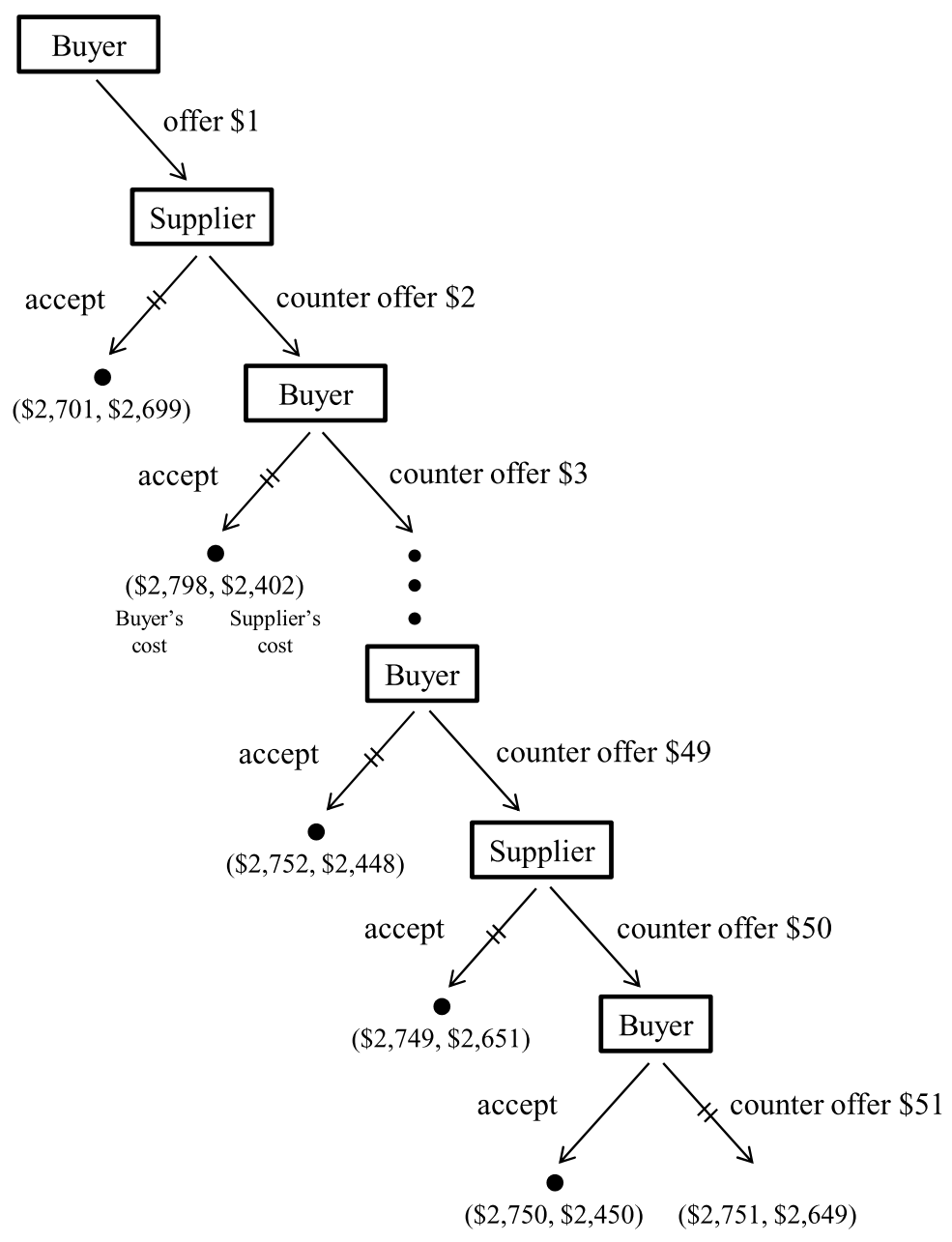

Fig. 3. Bargaining process for the Case 1 of the incomplete information game.

the supplier's side payment offer even though it is larger than the half of the buyer's delta value. Instead, the movement continues until the supplier is offered a side payment which equals to or exceeds the half of one's delta value. At this point, the supplier is in the position where it is more profitable to accept the buyer's counter offer. Thus the supplier accepts the side payment and agrees to use the buyer's optimal cycle.

Thus the equilibrium solution for this case is that the buyer pays the least amount that equals to or exceeds the half of the supplier's delta value and is offered to the supplier. When the data in Table 7 is applied to this case, if the buyer is the leader of the game, the game has the equilibrium where the buyer pays $\$ 151$ to the supplier and makes the supplier accept the buyer's optimal cycle. If the buyer is the follower of the game, the side payment can be lowered to $\$ 150$. The equilibrium for the Case 1 and 2 can be summarized as shown in Table 8. 
Table 8

Equilibrium for each case when the buyer is the leader

\begin{tabular}{llll}
\hline & Buyer's cost & Supplier's cost & Cycle chosen \\
\hline Case 1 & $\$ 2,750$ & $\$ 2,450$ & Supplier's cycle \\
Case 2 & $\$ 2,851$ & $\$ 2,549$ & Buyer's cycle \\
\hline
\end{tabular}

\subsection{Complete Information Game}

In the complete information game, each player can accurately calculate the other player's optimal cycle length and corresponding costs. In this situation, there are only two possible movements because both players can foresee the equilibrium of the game without performing the sequential offer and counteroffer procedure required in the incomplete game. Therefore, the players may arrive at the same equilibrium as the one of the incomplete information game in two movements.

The exact amount of side payment and the equilibrium point depend on whether the supplier's optimal cycle is feasible as well as who will be the leader of the game. Then, the equilibrium point of the complete information game will coincide with the one of the incomplete information game if the two games are in the same setting.

It should be noted finally that the bargaining process explained here is based on specific assumptions. A change in one or more of these assumptions will lead to another type of game with different equilibrium. For example, if a player is allowed to cease negotiations and terminate the bargaining process, the game will have an additional dimension and a different equilibrium may result. Finally, it is to be conceived that the method proposed in this paper is one way to reach an agreement; it is not an exhaustive analysis of all possible profit allotments. An analysis of numerous coordination mechanisms is beyond the scope of this paper and is left for future research.

\section{Summary}

In this study, a system with a buyer and a supplier who are attempting to establish a replenishment contract was analyzed. The buyer's inventory is depleted by the end customers' stochastic demand. The buyer replenishes the supplier's inventory at a regular interval up to a contracted order-up-to level.

For the investigated system, a mathematical model was formulated for each party, and a method to simultaneously determine an optimal cycle length and order-up-to level was developed. In a numerical test, the terms generated by the proposed method were verified to be the global optimal terms. A practical way to implement the terms was also suggested in order to efficiently coordinate the system. Finally, a rational method of reaching an agreement and dividing the additional profit produced by the contract was detailed. 
In future work, a more extensive study may be necessary to examine the coordination and profit allotment methods for a system with multiple types of products. It is also important to examine a system with non-normally distributed demand.

\section{References}

Anupindi, R., Akella, R. (1993). Diversification under supply uncertainty. Management Science, 39(8), 944963.

Banerjee, A. (1986). A supplier's pricing model under a customer's economic purchasing policy. Omega,14(5), 409-414.

Bendaya, M., Hariga, M. (2004). Integrated single vendor single buyer model with stochastic demand and variable lead time. International Journal of Production Economics, 92(1), 75-80.

Crowther, J.F. (1964). Rationale for quantity discounts. Harvard Business Review, 42, 121-127.

Dzemyda, G., Sakalauskas, L. (2010). Large-scale data analysis using heuristic methods. Informatica, 22(1), $1-10$.

Eynan, A., Kropp, D.H. (2007). Effective and simple EOQ-like solutions for stochastic demand periodic review systems. European Journal of Operational Research, 180(3), 1135-1143.

Goyal, S.K. (1987). Note-comment on: a generalized quantity discount pricing model to increase supplier's profits. Management Science, 33(12), 1635-1636.

Goyal, S.K. (1995). A one vendor multi buyer integrated inventory model: a comment. European Journal of Operational Research, 82(1), 209-210.

Gurnani, H. (2001). A study of quantity discount pricing models with different ordering structures: order coordination, order consolidation and multitier ordering hierarchy. International Journal of Production Economics, 72(3), 203-225.

Hill, R.M. (1997). The single vendor, single buyer integrated production inventory model with a generalized policy. European Journal of Operational Research, 97(3), 493-499.

Khouja, M. (2003). Optimizing inventory decisions in a multistage multi customer supply chain. Transportation Research Part E, 39(3), 193-208.

Kim, B.W., Leung, J.M.Y., Park, K.T., Zhang, G. and Lee, S.C. (2002). Configuring a manufacturing firm's supply network with multiple suppliers. IIE Transactions, 34(8), 663-667.

Klastorin, T.D., Moinzadeh, K. and Son, J. (2002). Coordinating orders in supply chains through price discounts. IIE Transactions, 34(8), 679-689.

Lu, L. (1995). Theory and methodology: a one vendor multi buyer integrated inventory model. European Journal of Operational Research, 81(2), 312-323.

Mishra, A.K. (2004). Selective discount for supplier buyer coordination using common replenishment epochs. European Journal of Operational Research, 153(3), 751-756.

Monahan, J.P. (1984). A quantity discount pricing model to increase vendor profits. Management Science, 30(6), $720-726$.

Munson, C.L., Rosenblatt, M.J. (2001). Coordinating a three level supply chain with quantity discounts. IIE Transactions, 33(5), 371-384.

Ouyang, L.Y., Wu, K.S. and Ho, C.H. (2004). Integrated vendor-buyer cooperative models with stochastic demand in controllable lead time. International Journal of Production Economics, 92(3), 255-266.

Rosenblatt, M.J., Lee, H.L. (1985). Improving profitability with quantity discounts under fixed demand. IIE Transactions, 17(4), 388-395.

Sarmah, S.P., Acharya, D. and Goyal, S.K. (2006). Buyer vendor coordination models in supply chain management, European Journal of Operational Research, 175(1), 1-15.

Sharafali, M., Co, H.C. (2000). Some models for understanding the cooperation between the supplier and the buyer. International Journal of Production Research, 38(15), 3425-3449.

Silver, E.A., Pyke, D.F. and Peterson, R. (1998). Inventory Management and Production Planning and Scheduling, 3rd edn. Wiley, New York.

Viswanathan, S., Piplani, R. (2001). Coordinating supply chain inventories through common replenishment epoch. European Journal of Operational Research, 129(2), 277-286. 


\section{Appendix 1}

Convexity of the Supplier Cost Function

Through partial differentiation of (7) with respect to $R$, we get

$$
\begin{aligned}
& \frac{\partial T C_{s}}{\partial R}\left(R, k_{s}\right)=-\frac{B}{R^{2}}+\frac{D^{2} h_{s}}{2 \rho}+\frac{k_{s} \sigma h_{s}}{2 \sqrt{R}}-\frac{\sigma b_{s} G_{u}\left(k_{s}\right)}{2 R \sqrt{R}} . \\
& \frac{\partial^{2} T C_{s}}{\partial R^{2}}=\frac{2 B}{R^{3}}-\frac{\sigma\left(k_{s} h_{s} R-6 b_{s} G_{u}\left(k_{s}\right)\right)}{4 R^{2} \sqrt{R}}
\end{aligned}
$$

The supplier's cost function, $T C_{s}\left(R, k_{s}\right)$, is a convex function with respect to $R$ if

$$
\frac{2 B}{R^{3}} \geqslant \frac{\sigma\left(k_{s} h_{s} R-6 b_{s} G_{u}\left(k_{s}\right)\right)}{4 R^{2} \sqrt{R}} .
$$

Partial differentiation of (7) with respect to $k_{s}$ gives

$$
\frac{\partial T C_{s}}{\partial k_{s}}\left(R, k_{s}\right)=\sigma h_{s} \sqrt{R}-\frac{\sigma b_{s}\left(1-F\left(k_{s}\right)\right)}{\sqrt{R}} .
$$

By setting $\frac{\partial T C_{s}}{\partial k_{s}}\left(R, k_{s}\right)$ to zero, we get $R=\frac{b_{s}}{h_{s}}\left(1-F\left(k_{s}\right)\right)$.

Taking the second-order partial derivative of (7) with respect to $k_{s}$, we get

$$
\frac{\partial^{2} T C_{s}}{\partial k_{s}^{2}}\left(R, k_{s}\right)=\frac{\sigma b_{s} f\left(k_{s}\right)}{\sqrt{R}} .
$$

Since $\frac{\partial^{2} T C_{s}}{\partial k_{s}^{2}}\left(R, k_{s}\right) \geqslant 0$, the supplier's cost function, $T C_{s}\left(R, k_{s}\right)$, is a convex function with respect to $k_{s}$.

\section{Appendix 2}

\section{Convexity of the Buyer Cost Function}

Taking the second-order partial derivative of (23) with respect to $k$, we get

$$
\begin{aligned}
\frac{\partial^{2} T C_{b}}{\partial k_{b}^{2}}\left(R, k_{b}\right) & =-\frac{B}{R} \sigma \sqrt{R+L}\left(-\frac{\partial F\left(k_{b}\right)}{\partial k_{b}}\right) \\
& =\frac{B}{R} \sigma \sqrt{R+L} f\left(k_{b}\right) \geqslant 0 .
\end{aligned}
$$

Thus, the buyer's cost function, $T C_{b}\left(R, k_{b}\right)$, is a convex function with respect to $k_{b}$. 
Taking the second-order partial derivative of (23) with respect to $R$, we get

$$
\begin{aligned}
\frac{\partial^{2} T C_{b}}{\partial R^{2}}\left(R, k_{b}\right)= & \frac{2 A}{R^{3}}-\frac{\sigma k_{b} h_{b}}{4(R+L) \sqrt{R+L}} \\
& +\sigma B G_{u}\left(k_{b}\right)\left(\frac{3 R^{2}+12 R L+8 L^{2}}{2 R^{3}(R+L)}\right) .
\end{aligned}
$$

Thus, if $\frac{\partial^{2} T C_{b}}{\partial R^{2}}\left(R, k_{b}\right) \geqslant 0$, the buyer's cost function is convex with respect to $R$.

J.S. Kim is a professor of industrial and management engineering at Hanyang University in Korea. He received his doctor of engineering and MS degrees from the University of California at Berkeley. His areas of research include mathematical programming, inventory control, game theory applications to logistic problems.

W.C. Jeong received his MS degree in industrial and management engineering from Hanyang University. He is currently pursuing his $\mathrm{PhD}$ degree in industrial and management engineering from Hanyang University. His research topics include joint replenishment problem and contract problems in logistics field. 


\section{Koordinavimo modelis užsakymu politikai}

\section{Jong Soo KIM, Won Chan JEONG}

Straipsnyje nagrinėjama logistinė sistema, skirta gaminti ir tiekti vieną produktą, sąveikaujanti su pirkejju, gaunančiu ir parduodančiu produktą galutiniam vartotojui. Nagrinėjamas matematinis sistemos elgesio modelis, leidžiantis nustatyti optimalu verslo ciklo ilgi bei užsakymu lygi abiem šalims. Gautu rezultatu analizė patvirtino, kad sukurtas metodas leidžia apibréžti optimalius valdymo parametrus per trumpą laiką. Darbe pasiūlytas koordinavimo mechanizmas, pagrịstas optimalia užsakymų politika, kuris teikia privalumų kiekvienai pusei, palyginus su nekoordinuojama situacija. 